Religare, ISSN: 19826605, v.14, n.1, agosto de 2017, p. 28-59.

\title{
Feições expressivas do movimento espirita brasileiro
}

\author{
Expressives features from Brazilian Spirit Moviment
}

\author{
André Ricardo de Souza ${ }^{1}$ \\ Célia da Graça Arribas² \\ Pedro Simões ${ }^{3}$
}

\section{Resumo}

Em nenhum outro país quanto o Brasil há um movimento espírita tão demograficamente abrangente e também rico em termos de interpretações do chamado tríplice aspecto do espiritismo: filosofia, ciência e religião. Desde sua implantação na década de 1860, há um segmento que valoriza bastante sua dimensão intelectualista, filosófica e científica, de modo a haver organizações e ativistas com posturas que chegam a ser bastante cientificistas. Porém a ênfase no aspecto religioso, historicamente, sobressaiu e prepondera no espiritismo nacional, havendo duas destacadas facetas dela. Uma paulista, que foi iniciada pelo militar orientalista Edgard Armond, e a outra mineira, protagonizada pelo médium Chico Xavier e seu mentor espiritual Emmanuel. Ambas estimulam o estudo bíblico do Novo Testamento, embora esta proponha mais aprofundamento do que aquela, sendo que ambas enfatizam a identidade cristã do espiritismo. Este artigo discute tais feições do movimento espírita brasileiro.

Palavras-chave: movimento espírita; cientificismo; Edgard Armond; Chico Xavier; Emmanuel; Novo Testamento.

\section{Abstract}

In no other country as in Brazil there is a spirit movement as demographically spread and also rich in meanings of the called triple aspect of spiritism: philosophy,

\footnotetext{
${ }^{1}$ Doutor em sociologia pela USP e professor do Departamento de Sociologia da UFSCar. E-mail: anrisouza@uol.com.br.

${ }^{2}$ Professora Adjunta do Departamento de Ciências Sociais da Universidade Federal de Juiz de Fora e Diretora do Centro de Pesquisas Sociais da UFJF.

${ }^{3}$ Professor Associado III da Universidade Federal do Rio de Janeiro com atuação (provisória) no Departamento de Sociologia Política da Universidade Federal de Santa Catarina (UFSC) . É líder do grupo de pesquisa "Laboratório de Dados Sociais" (ESS/UFRJ), além de estar vinculado ao Núcleo de Estudos de Religião, Economia e Política (NEREP/UFSCAR) e ao grupo "Consciência da Doença" do Laboratório de Psiquiatria Geriátrica (IPUB/UFRJ).
} 
Religare, ISSN: 19826605, v.14, n.1, agosto de 2017, p. 28-59.

science and religion. Since it implantantion in decade of 1860, there is a segment that value a lot your intelectualist, philosophic and cientific dimension, in a way to have organizations and activers with postures that are very much cientificists. Although, the emphasis in religious aspect, historically, standed out and prevail in national spiritism, having two highlighted facets of it. One paulist, it had beginned by the deceased military and orientalist Edgard Armond and the other from Minas Gerais that had starred by the also deceased medium Chico Xavier and his spiritual mentor Emmanuel. Both stimulate the study of the Biblical New Testament, nevertheless this one proposes a deepening of that one, being that both emphasize the Christian identity of the spiritism. This article discusses such features of the Brazilian Spiritist movement.

Key-words: Spiritist movement, cientificism, Edgard Armond, Chico Xavier, Emmanuel, New Testament

\section{Introdução}

O espiritismo ${ }^{4}$ se constitui como a terceira maior religião do Brasil, atrás do catolicismo e do protestantismo, abrangendo $2 \%$ da população, conforme o censo realizado pelo Instituto Brasileiro de Geografia e Estatística (IBGE) em 2010. Há, no entanto, uma discussão se parte dos $8 \%$ que se declaram sem religião, e mesmo alguma parcela dos 64,6\% que se declaram católicos, seriam espíritas não assumidos como tal ${ }^{5}$, em face da controvérsia sobre a identidade do espiritismo como religião (Lewgoy, 2010). Eis uma questão ainda presente no movimento espírita, relacionada à interpretação da tríplice dimensão dessa doutrina codificada na França por Allan Kardec, a partir de 1857: filosofia, ciência e religião (Araujo, 2016).

Este artigo inicia discutindo a relação entre religião e ciência, tanto em termos do que publicou o fundador francês quanto dos desdobramentos históricos e também contemporâneos no conjunto de espíritas brasileiros. São discutidos

\footnotetext{
${ }^{4}$ Embora nas ciências sociais da religião ainda se diga 'espiritismo kardecista' ou 'kardecismo', em contraste com o que foi chamado de 'espiritismo de umbanda' (a umbanda propriamente dita), nós empregamos apenas espiritismo.

${ }^{5}$ Há que se dizer também que uma parte dos espíritas são umbandistas que não se declaram deste modo.
} 
Religare, ISSN: 19826605, v.14, n.1, agosto de 2017, p. 28-59.

aspectos dos principais atores e organizações com viés cientificista. Mas como a ênfase religiosa predomina em tal movimento, o texto apresenta duas destacadas vertentes desse tipo. A primeira delas, bastante legitimada e institucionalizada no Estado de São Paulo, é personalizada no falecido oficial militar Edgard Armond. Entre as décadas de 1940 e 1960, de modo enérgico, esse líder espírita paulista imprimiu a chamada padronização dos passes e também estabeleceu um rígido programa educativo com características iniciáticas, combinando elementos doutrinários espíritas com outros de matriz orientalista, além do estudo dos textos que compõem o Novo Testamento, a partir de mediações e referências próprias.

Já a segunda faceta religiosa proeminente surgiu e prossegue se difundindo a partir de Minas Gerais, tendo como referência inicial e maior o médium Francisco de Paula Cândido Xavier, conhecido como Chico Xavier, figura mais importante do século XX espiritismo mundial ${ }^{6}$. Assim como ele, outros médiuns, além de estudiosos e reconhecidos oradores mineiros, igualmente orientados ou inspirados pelo espírito denominado Emmanuel, vão incentivar o estudo aprofundado do Novo Testamento, recorrendo ao texto traduzido direto do grego, além de dicionários bíblicos e livros psicografados por Xavier. Tal ênfase no cultivo do que é sinteticamente chamado de "Evangelho", não só reforça a identidade religiosa do espiritismo como também o reafirma enquanto religião cristã, sociologicamente, ao lado do catolicismo e do protestantismo.

\section{Espiritismo e ciência}

O espiritismo guarda uma marca de origem, na sua tripla identidade, como ciência, religião e filosofia, marca legada e contida na própria codificação de Kardec.

\footnotetext{
${ }_{6}^{6}$ Encontra-se presente hoje em mais de trinta países, sendo organizado pelo Conselho Espírita Internacional - CEI (Lewgoy, 2011).
} 
Religare, ISSN: 19826605, v.14, n.1, agosto de 2017, p. 28-59.

Entretanto, a variedade de perspectivas explicitadas pelo codificador, ao invés de ser um sinal de múltiplas qualidades da sua obra, foi o objeto de "cismas" (Signates, 2013) e disputas entre seus adeptos (Arribas, 2010 e 2013, Camurça et. al. 2017, Giumbelli, 1997, Lewgoy, 2006).

Ativistas e analistas da religião têm debatido qual, afinal, a identidade do espiritismo e como esta tem se modificado ao longo da sua história. Se entre os primeiros há uma busca de marcar posição e demonstrar que uma ênfase deve sobressair às demais, entre os pesquisadores, principalmente antropólogos, há a tentativa de sistematização de uma narrativa histórica, apresentando seus dilemas e contradições internos, mas sem uma tomada de posição. Neste último caso, é dada pouca importância ao que está escrito na codificação kardeciana, sendo o foco na própria dinâmica dos atores e como eles constroem, fundamentam e legitimam socialmente suas ações.

De fato, esse tema é controverso e alguns exemplos internos ao campo espírita podem ser dados para demonstrar o porquê do debate. Em O evangelho segundo o espiritismo (livro básico da codificação), por exemplo, há a uma epígrafe elucidativa: "fé inabalável só o é a que pode encarar frente a frente a razão, em todas as épocas da humanidade". Parte dos espíritas compreendeu que os avanços da razão e da ciência deveriam andar pari passo com o entendimento do espiritismo. Este já é, por si só, ponto de intenso debate, afinal, de que razão se trata? Da positivista, contemporânea à Kardec (Signates, 2014)? A ciência não avançou, superando as descobertas próprias ao século XIX? Então, como não incorporar os novos entendimentos e descobertas para fazer avançar também a compreensão do espiritismo?

Além daquela epígrafe, há outras menções - em Obras Póstumas, O que é o espiritismo e na Revista Espírita - sobre a relação entre ciência e religião nos escritos de Kardec. Elas parecem sugerir que, para o codificador, o espiritismo é uma ciência, 
Religare, ISSN: 19826605, v.14, n.1, agosto de 2017, p. 28-59.

por tratar "da natureza, origem e destino dos espíritos", com efeitos religiosos, mas sem ser propriamente uma religião. Esta forma de entendimento foi, entretanto, objeto de questionamento, dado que, historicamente, o movimento espírita acabou se configurando, na verdade, como uma religião com fundamentos científicos.

Na história do espiritismo, houve disputas internas sobre a prevalência de um sentido a outro. Nelas, aqueles que deram mais ênfase à ciência tornaram-se minoritários frente aos que lhe conferiram caráter religioso. Esses dois elementos da identidade espírita se apresentam, com maior ou menor ênfase, a depender do ator em foco.

\subsection{Cismas, cisões e unidade}

Nos textos que tratam da história do espiritismo (Arribas, 2010 e 2013, Camurça et. al. 2017, Giumbelli, 1997, Lewgoy, 2006) há um consenso de que o debate sobre sua identidade reporta à época de sua entrada no Brasil. Uma característica espírita ajuda a explicar as divergências da apropriação da codificação de Kardec: entre os adeptos não há uma hierarquia formalmente instituída em sentido religioso. Assim, cada grupo pode fazer sua própria interpretação da obra kardeciana (Lewgoy, 2006). A formação da Federação Espírita Brasileira (FEB), em 1884, não foi suficiente para estabelecer efetivamente uma diretriz única aos centros espíritas, a despeito da pretensão de seus dirigentes. Em parte, isso se deve ao fato de a adesão à FEB ser voluntária.

No entanto, dois fatos ajudaram a conferir homogeneidade ao movimento espírita brasileiro. O primeiro foi o chamado Pacto Áureo, ocorrido em 1949. Através dele se buscou a unificação das tendências existentes até então, a saber: os "científicos", que estavam "exclusivamente preocupados com o que chamavam de experiência fenomenológica" e cujo foco eram as "aparições dos espíritos e seus efeitos (Arribas, 2013, p. 8), e os "místicos" ou "religiosos", voltados ao estudo da 
Religare, ISSN: 19826605, v.14, n.1, agosto de 2017, p. 28-59.

moral cristã7. Tal unificação buscava superar as diferenças de perspectivas, fazendo com que o espiritismo não fosse visto como ciência, religião ou filosofia, isoladamente, de modo que esses três elementos fossem considerados partes constitutivas e inalienáveis da codificação.

Outro ponto relevante foi o peso da influência de Chico Xavier e do seu guia espiritual Emmanuel no reforço da tendência religiosa (Lewgoy, 2004). As federativas e demais instituições espíritas passaram a incorporar esta tendência, legitimando-a cada vez mais. Com isso, o estudo da codificação kardeciana tornouse uma forma de identificação religiosa.

Em paralelo a esta vertente do espiritismo no Brasil, outras iniciativas deram mais ênfase ao aspecto científico do que religioso. Essas últimas passaram despercebidas, em alguma medida, frente à hegemonia da FEB (Lewgoy, 2008, Arribas, 2010). No entanto, elas adquiriram visibilidade como formas alternativas de se compreender o espiritismo.

O fato é que, a despeito das rupturas, as continuidades também estiveram presentes. Elas ocorreram seja através de instituições, seja na forma de publicações. A possibilidade de manutenção dos cientificistas entre os espíritas ocorreu de três modos, apresentadas aqui sem uma preocupaçãocronológica. No primeiro modo, a base de legitimidade é a narrativa espiritual, ou seja, a recepção mediúnica de obras que dialogam com o universo científico; no segundo, os espíritas legitimam as apropriação e interlocução com a ciência a partir de suas qualificações profissionais; por fim, no terceiro, a legitimidade deriva da mediação de uma intercessão com o universo acadêmico. Vejamos cada um desses três tipos.

\subsection{A ciência dos espiritos}

${ }^{7}$ Giumbelli (1997), Arribas (2010) e Camurça et. al. (2017) mostram que essa divisão não era de todo excludente, mas tratava-se, antes, de diferenças de ênfase em um ou outro aspecto do espiritismo. 
Religare, ISSN: 19826605, v.14, n.1, agosto de 2017, p. 28-59.

A forma mais legitimada da ciência no universo espírita se dá através de uma mensagem, ou publicação de um livro mediúnico. Neste caso, são os próprios espíritos que o fazem, recuperando, com isso, ascendência moral e primazia ante às abordagens dos encarnados.

O caso mais típico está em alguns livros atribuídos ao espírito André Luiz e psicografados por Chico Xavier. Lewgoy (2006) chama atenção, particularmente, para Nos domínios da mediunidade (1955) e Evolução em dois mundos (1958). Nessas obras a ciência é apresentada como revelação, ou seja, sem comprovação, citação de fontes e outras referências inerentes à apresentação de dados ou resultados científicos.

Outra expressão desta forma de incorporação da ciência está na atuação do médium baiano Divaldo Franco. Dentre seus livros psicografados, dezesseis se destacam por comporem a Série psicológica, iniciada em 1989 e atribuída ao espírito Joanna de Ângelis, sua mentora. Nestas obras, a autora espiritual não fundamenta sua argumentação religiosa apenas em conceitos cristãos e nos livros de Kardec, mas também na psicologia de Carl Gustav Jung. Chama atenção o fato de ela também não utilizar o modo acadêmico de escrita científica, com citações, apresentação e explicitação dos conceitos e referências teóricas. Este posicionamento diferencia-se, substantivamente, de outras obras psicografadas pelo próprio médium, com enfoque estritamente religioso.

Nesse sentido, tais obras compõem outro universo de publicações no espiritismo, diferenciando-se daquelas mais tradicionais, de cunho religioso-cristão, cuja ênfase é no aconselhamento moral. Elas voltam-se para um público mais restrito, com capacidade de abstração e compreensão de termos próprios ao vocabulário junguiano, que não é, necessariamente, dominado pelos adeptos do espiritismo. Tais trabalhos abriram um campo de investigação em que muitos 
Religare, ISSN: 19826605, v.14, n.1, agosto de 2017, p. 28-59.

autores espíritas começaram a fundamentar suas abordagens, não somente, na explicação doutrinária, mas também na chamada psicologia transpessoal.

Tanto a abordagem atribuída à Joanna de Ângelis quanto a relacionada ao espírito André Luiz não são objeto de controvérsias nas lides mais tradicionais (religiosas) espíritas, porque têm origem espiritual e são derivadas das duas maiores expressões mediúnicas do espiritismo contemporâneo. Suas explicações científicas se casam e se interpenetram com aquelas relativas à moral cristã e aos textos kardecianos.

\subsection{Os profissionais e a ciência}

A segunda forma de incorporação da ciência pelos espíritas ocorre derivada da legitimidade profissional dos seus membros. São os que utilizam sua formação profissional para estabelecer uma relação entre suas práticas e o universo espírita. Não tendo a mesma legitimidade dos espíritos escritores através de médiuns, valemse do status que adquiriram. Assim como na "ciência dos espíritos", não temos aqui uma negação da forma religiosa de apropriação do espiritismo, por um enfoque mais científico, mas sim a busca de qualificação do discurso religioso mediante o conhecimento profissional.

Ainda que não discutam, nos fundamentos, a relação entre as crenças espíritas e os resultados de pesquisas científicas, este modo de apropriação da ciência, assim como o anterior (excetuando o caso de André Luiz), recheiam as intervenções do espiritismo de conceitos e proposições alheios ao universo doutrinário. Nem sempre concordantes com concepções como fé, caridade, vida futura, vidas passadas, entre tantas outras relevantes no espiritismo, estas novidades trazem um viés, necessariamente, parcial para as interpretações espíritas, em contraposição ao ideário de ser o espiritismo outra "revelação das Leis de Deus", como dito em Evangelho segundo o espiritismo. 
Religare, ISSN: 19826605, v.14, n.1, agosto de 2017, p. 28-59.

Quando um espírita se vale das teorias e metodologias que utiliza para sua profissão, seja qual for, e afirma que esse saber tem respaldo (ou se associa) ao conhecimento espírita, ele está deslegitimando as demais. Como ficam os psicólogos espíritas freudianos, ao legitimar-se o discurso junguiano; ou os educadores montessorianos, ao afirmar-se a relação da doutrina espírita com uma educação construtivista? Enfim, se estas formas de contribuição dos profissionais têm sentido para os seus agentes, elas - por não enfrentarem o debate dos fundamentos e por partirem de uma postura não científica de colocar em dúvida todo o tipo de conhecimento, inclusive os advindos dos espíritos - terminam, de algum modo, criando um saber parcial no universo espírita, em contraposição ao discurso universalista.

Alguns exemplos de profissionais desse tipo são Rossandro Klinjey', Andrei Moreira $^{9}$, Alírio de Cerqueira ${ }^{10}$, entre outros que associam conceitos de autoajuda motivacional, psicologia transpessoal, constelação familiar e psicanálise ao universo espírita, tendo como base suas qualificações profissionais. Entretanto, seus discursos só têm eco ante sua clientela e dentro do movimento espírita (suas publicações são realizadas por editoras espíritas). Suas ideias não são publicadas em revistas científicas, onde seus argumentos seriam analisados por pares, auferindo-lhes legitimidade científico-acadêmica por obedecer aos critérios que compõem esse tipo de conhecimento.

\subsection{Os cientistas do espiritismo}

\footnotetext{
8 Autor de dois livros, ambos publicados em 2016, o primeiro editado pela Letra Mais e o segundo pela Federação Espírita do Estado de Goiás. No Facebook da editora Letra Mais consta apenas esta publicação do autor e todo o conteúdo da página virtual refere-se ao mesmo. Ao que indica, trata-se de uma editora do próprio autor. Veja Klinjey (2016).

${ }^{9}$ Escreveu sete livros, todos publicados após 2010 e editados pela Associação Médico- Espírita. Veja Moreira (2012).

${ }^{10}$ Autor de vários livros, todos por editoras espíritas. Veja Cerqueira (2009). Uma análise de como o autor faz uso da psicologia transpessoal em suas obras pode ser encontrada em Simões (2015, p. 9394).
} 
Religare, ISSN: 19826605, v.14, n.1, agosto de 2017, p. 28-59.

O terceiro grupo é composto por indivíduos e grupos que buscam atuar cientificamente em relação ao próprio espiritismo. A legitimação, neste caso, não se dá através de clientela profissional ou do reconhecimento no próprio movimento espírita, mas sim via academia, tomando o espiritismo como objeto de investigação. Ou seja, os fundamentos espíritas chegam a ser questionados cientificamente, tudo em prol do avanço no conhecimento.

Um exemplo institucional é a Confederação Espírita Pan-Americana (CEPA), que foi fundada em 1946, durante o primeiro Congresso Espírita Pan-Americano, realizado em Buenos Aires. Desde sua origem, a posição da CEPA foi de rejeição da vertente religiosa do espiritismo (Lewgoy, 2011). Seus integrantes "proclamam um espiritismo laico e livre-pensador, reivindicando tais ideias como originais do próprio Allan Kardec". Além disso, posicionam-se "pela natureza científica e não religiosa do espiritismo". Por fim, propuseram "um processo de atualização da doutrina espírita" o que foi "considerado inaceitável pelas lideranças espíritas brasileiras" (Signates, 2013, p. 46).

Outro exemplo institucional, embora não com o mesmo viés tão cientificista, é o da Associação Médico-Espírita (AME). Fundada em 1995, ela visa propiciar a contribuição do espiritismo à medicina, realizando um diálogo entre os textos espíritas e os profissionais da saúde. Essa organização atenua o cientificismo, pois tanto coloca o espiritismo como objeto de estudo científico, quanto aceita seus fundamentos religiosos. Além disso, alguns de seus integrantes não chegam a estabelecer um sentido estritamente científico às suas abordagens, remetendo-se ao campo profissional específico em que atuam. 
Religare, ISSN: 19826605, v.14, n.1, agosto de 2017, p. 28-59.

Chama atenção o fato de seus principais líderes, como a já falecida Marlene Nobre $^{11}$, fundadora da instituição e de seu atual presidente, Gilson Luís Roberto, não se afirmarem como pesquisadores, mas tão somente como médicos. No entanto, esta não é uma posição unívoca. Na página da associação na internet (www.amebrasil.org.br) há referência a várias publicações em periódicos nacionais e internacionais fazendo a interlocução entre o espiritismo e os vários campos de conhecimento correlatos à medicina. A Associação tem como veículo de divulgação de seus trabalhos a Revista Saúde e Espiritualidade e a editora própria (AME Editora), embora seus integrantes não deixem de publicar em periódicos acadêmicos.

Outro exemplo é a Liga de Pesquisadores do Espiritismo (LIHPE). Fundada em 2002 por Eduardo Carvalho Monteiro - nome original: Liga dos Historiadores e Pesquisadores Espíritas - tem como objetivo “tentar agregar pesquisadores da academia e de fora dela para trocar informações sobre os seus trabalhos e construir um Centro de Cultura, Documentação e Pesquisa"12. Trata-se de uma organização virtual que busca agregar pesquisas acadêmicas sobre o espiritismo, independentemente da área de conhecimento.

Os encontros de pesquisadores promovidos pela LIHPE, já em sua $13^{\underline{a}}$ edição, contêm um caráter eminentemente acadêmico. Ou seja, embora os trabalhos não precisem ser derivados de pesquisas acadêmicas, eles devem conter indicação de metodologia e passam por avaliação duplo cego (os avaliadores desconhecem o autor do artigo). As temáticas dos últimos encontros expressam a ênfase desta

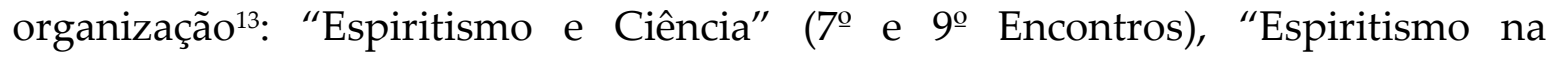
atualidade: das práticas cotidianas ao meio acadêmico" ( $8^{\underline{o}}$ Encontro), "Pesquisa

\footnotetext{
11 "Marlene Nobre foi "chamada" para trabalhar com Chico Xavier ao final dos anos 1950, tendo permanecido cerca de cinco anos como pessoa de confiança ao lado do médium. Esse apadrinhamento/mentoria garantiu-lhe lugar de absoluto destaque no espiritismo brasileiro, assim como alavancou o crescimento da proposta da AME" (Lewgoy, 2011, p. 100).

${ }_{12}$ Fonte: site http://www.lihpe.net/wordpress/ consultado em abril de 2017.

${ }^{13}$ Os primeiros seis encontros não tiveram um tema central.
} 
Religare, ISSN: 19826605, v.14, n.1, agosto de 2017, p. 28-59.

Espírita: Passado, Presente e Futuro” (10ํㅡㄹ Encontro), “Panorama atual das pesquisas científicas sobre a reencarnação" (11ํㅡㄹ Encontro), "Mediunidade: pesquisa e história” (12ํㅡㄹ Encontro) e "Preces e Curas Espirituais" (13º Encontro).

Observando os temas verifica-se que, além da menção ao espiritismo, os termos "pesquisa" e "ciência" ou "acadêmico" dão o tom do debate. Não há menção ao Evangelho, a Jesus, à moral cristã ou a qualquer ideia de religião. A referência é o diálogo da obra de Kardec com a academia e os modelos científicos de pesquisa. Mas ainda que confiram grande ênfase nos aspectos científicos, esses encontros da Liga não deixam de ter elementos de caráter religioso. São feitas preces, como nas convencionais reuniões espíritas.

\section{No comando, Edgard Armond: o nascimento de um espiritismo esotérico}

Ao longo do processo de adensamento, ao mesmo tempo institucional e teórico, pelo qual vem passando o espiritismo brasileiro, alguns momentos de sua história são como verdadeiros divisores de águas. Este é o caso, por exemplo, da entrada em cena, nos anos 1940, de Edgard Armond (1894-1982), coronel da Força Pública do Estado de São Paulo - atual Polícia Militar paulista - no comando da Federação Espírita do Estado São Paulo (FEESP).

É comum ouvirmos ainda hoje dos seguidores de Armond, ou pelo menos daqueles que nutrem afinidades com sua obra, que antes da entrada do coronel, os espíritas não sabiam o que fazer com o espiritismo nas mãos, tamanho desgoverno em que supostamente se encontrava. Educador, instrutor, unificador, polêmico, orientalista, mestre, maçom, empreendedor, rigoroso, metódico, disciplinador: esses são alguns dos adjetivos associados a ele, ressaltados, não só nas biografias, mas 
Religare, ISSN: 19826605, v.14, n.1, agosto de 2017, p. 28-59.

também em todas as fontes a seu respeito, tanto no meio espírita quanto na sua vida profissional $^{14}$.

Afeito ao estudo comparado das religiões e filosofias orientalistas, Armond começou na adolescência a se sentir atraído por elas, algo que iria marcar a sua vida. A tendência aos estudos espiritualistas já chamava a sua atenção para questões como reencarnação, karma e imortalidade da alma, ideias ainda muito distantes da cultura religiosa predominante no Brasil daquele tempo. Não por acaso Armond se iniciaria na maçonaria, guiado por sua forte curiosidade sobre os "mistérios" da vida e por sua disposição aos conhecimentos esotéricos (Silva Jr., 2010, p. 81). Fato intrigante é que ele não limitava seus estudos a essa ou àquela corrente esotérica, orientalista ou espiritualista. Anotações suas sobre o zodíaco em seu caderno de estudos maçônicos apontavam para o conhecimento inclusive do espiritismo, ou pelo menos do livro $A$ Gênese, de Allan Kardec (Silva Jr., 2010, p. 89). A Cabala judaica e os ensinamentos de origem hinduísta e egípcia foram outros tantos objetos de grande interesse ${ }^{15}$.

Em 1938, vítima de um acidente que foi responsável, um ano depois, por sua reforma por invalidez na Força Pública, Armond já havia participado, de forma esporádica e sem grande comprometimento, de algumas reuniões espíritas. Seu primeiro contato se deu em 1936, quando foi convidado a participar de reuniões na FEESP. Essa aproximação, no entanto, não significou a sua pronta adesão ao espiritismo. Em 1939, prestes então a se aposentar, escreveu seus dois primeiros livros: Pensamentos e Contos espiritualistas. Um dos temas abordados tratava da

\footnotetext{
${ }^{14}$ Além de pesquisas em arquivos, revistas, jornais e inúmeros sites, utilizamos ao longo deste artigo as principais biografias de Armond: duas de seu filho (Ismael Armond, 2001 e 2002) e outra de Edelso da Silva Jr. (2010). Particularmente interessante é a entrevista dada no dia 23/10/2010 por Silva Junior ao programa "Ramatís" da TV Mundo Maior, uma emissora da Fundação Espírita André Luiz. In: http://www.tvmundomaior.com.br/ramatis/ Acessado em 02/04/2012.

${ }^{15}$ Seu filho conta que já desde a década de 1920 Armond mantinha "contatos pessoais com líderes esoteristas, ocultistas e espíritas de então; entre outros, com Krishnamurti, Krum Heler, Jenerajadasa, Raul Silva (...) e o famoso médium Mirabelli, com destaque nos trabalhos de efeitos físicos, bastante em evidência naqueles dias" (Ismael Armond, 2001: 27).
} 
Religare, ISSN: 19826605, v.14, n.1, agosto de 2017, p. 28-59.

história dos "elementais" - seres ou forças singulares, multiformes e invisíveis, presentes na natureza, além do plano físico - tema que incomodou o meio espírita por fazer referência à mitologia e ao paganismo (Silva Jr., 2010, p. 95).

Tudo se passava em 1940, momento delicado para o movimento espírita paulista. Praticamente no mesmo ano em que uma crise assomava - tanto a União Federativa Espírita Paulista (UFEP), que perdia seus líderes, quanto a FEESP, carente de direção permanente e de dinheiro - aposentava-se por invalidez o comandante Armond. Se antes ele já demonstrava disposição às concepções espiritualistas, foi, sobretudo, ao se aposentar, que seu tempo passaria a ser destinado quase que exclusivamente aos estudos de tal ordem, e mais propriamente, aos estudos sobre espiritismo, ou, pelo menos, o que ele entendia ser espiritismo como diziam seus críticos, sobremaneira o respeitado filósofo espírita, José Herculano Pires (Arribas, 2014). Foi justamente em 1940 que Armond começou a frequentar a FEESP na qualidade de secretário geral, e é interessante apontar que sua introdução no corpo administrativo da instituição teve implicações significativas para o desenvolvimento do movimento espírita paulista, com consequências importantes para o movimento espírita nacional. Preocupado com a fragmentação dos espíritas, foi dele a iniciativa de congregar, em 1946, várias instituições paulistas num novo organismo a que deu o nome de União Social Espírita (USE), posteriormente chamada de União das Sociedades Espíritas, mantendo, assim, a mesma sigla ${ }^{16}$.

Militar, Armond sempre foi afeito aos estudos metódicos e minuciosos que o próprio ethos profissional demanda. Seus inúmeros relatórios militares e o seu caderno de anotações da maçonaria são exemplos disso. Muitos dos seus conhecimentos prévios ao contato com o espiritismo foram usados por ele para

\footnotetext{
${ }^{16}$ Mais tarde, a USE tornou-se a federativa paulista vinculada ao Conselho Federativo Nacional da
} FEB, distanciando-se paulatinamente dos padrões estabelecidos pelo comandante. 
Religare, ISSN: 19826605, v.14, n.1, agosto de 2017, p. 28-59.

corroborar o que entendia ser a doutrina espírita. Como dito, havia entre seus pares quem questionava isso. Mas o inegável é que essa predisposição fez da sua adesão ao espiritismo, sobretudo porque usufruía de um cargo de dirigente, uma espécie de laboratório para a aplicação prática de seus conhecimentos. Vejamos um exemplo. Quando Armond chegou ao espiritismo, suas práticas se resumiam basicamente a dois tipos de reuniões: (1) as palestras, que podiam ser dadas em salões, auditórios ou até mesmo em clubes; a participação era livre e sem comprometimento, e os temas eram variáveis; (2) as reuniões mediúnicas de desobsessão e de efeitos físicos, bastante correntes à época, práticas que os espíritas muitas vezes denominaram de "mediunismo sem nenhum vínculo doutrinário" e que por isso mesmo abriam brechas para os mais diversos tipos de sincretismos. Pode-se dizer que cada dirigente de núcleo espírita tinha seu modus operandi, o que dificultava a uniformização do espiritismo, tanto mais porque não havia tanta preocupação em "formar" os chamados trabalhadores espíritas. Havia pouca preocupação também em instruir e orientar os médiuns que frequentavam as reuniões, sendo que parte deles, argumentava-se, participava a título de entretenimento. Até aquele momento, existia de fato pouca movimentação voltada a formular as bases de um estudo sistemático da doutrina. A entrada de Armond na FEESP, portanto, iria mudar definitivamente esse quadro ao propor "um espiritismo de vivos", isto é, algo que deixasse, por um tempo, os "espíritos desencarnados" de escanteio e fizesse com que os "espíritas encarnados" passassem a agir mais ativamente no mundo, fosse através das obras de caridade, fosse na participação individual nas instituições ou fosse no envolvimento consciente e engajado.

O militar paulista começava as suas tarefas numa São Paulo que já havia passado pelas agitações da Revolução Constitucionalista. A figura de um comandante da Força Pública dava ao movimento espírita paulista uma legitimidade social relevante, além de proporcionar aos próprios espíritas uma 
Religare, ISSN: 19826605, v.14, n.1, agosto de 2017, p. 28-59.

segurança significativa na hora de aceitar as inúmeras inovações que o comandante Armond punha em marcha. O sentido de obediência falou alto. É interessante notar que Edgard Armond conservou - e justamente por conta disso ficou conhecido - a sua insígnia de "comandante", só que não mais dos policiais, mas sim dos espíritas. A autoridade enérgica que exercia entre os adeptos - que pareciam estar carentes de uma direção firme ${ }^{17}$ - talvez seja um dos fatores que explicam a subordinação por parte dos espíritas paulistas, ou pelo menos de grande parte deles, às suas inovações e à sua personalidade, muitas vezes caracterizada como austera, sisuda, de pouco riso e pouca conversa, mas reconhecidamente de muito trabalho (O Semeador, janeiro de 1983).

Sua primeira atitude na direção da FEESP foi a criação, em 1942, do que ele denominou de Grupo Razin, uma espécie de "regimento" composto por médiuns de sua confiança. O objetivo do agrupamento era fazer conexões as mais seguras possíveis com os "espíritos mentores" da FEESP, já que, como Armond diagnosticava, havia uma carência no movimento espírita, tanto de diretrizes quanto de médiuns preparados. Razin era o nome de um dos espíritos protetores de Armond. Sua descrição física, segundo os médiuns videntes, é a de um espírito com feições e vestes orientais, com o qual Armond, em vidas passadas no Oriente, teria tido relações muito próximas (Silva Jr., 2010: 265). E foi através do Grupo Razin que Armond recebeu uma mensagem atribuída ao Anjo Ismael ${ }^{18}$ dando-lhe as primeiras instruções de como conduzir a federativa paulista. Foi através dos médiuns desse

\footnotetext{
17 Para mais informações, ver Arribas (2010 e 2014).

${ }_{18}$ Anjo Ismael, segundo o livro Brasil: coração do mundo, pátria do evangelho, psicografado por Chico Xavier (e ditado pelo espírito de Humberto de Campos), em 1938, seria o preposto imediato de Jesus Cristo e a quem teria sido incumbida a tarefa de guiar os rumos do Brasil na qualidade de seu anjo guardião - espécie de santo padroeiro à la espírita. A mensagem dizia: "Você foi o escolhido e aqui será o chefe, e esta é a espada do comando". E encerrou dizendo: "para te auxiliar nos primeiros dias, como conselheiros e elementos de ligação conosco, colocaremos junto de ti (...) companheiros valorosos" (Silva Jr., 2010: 148). Escreve o biógrafo de Armond que "essa multidão de guerreiros pertencia à Fraternidade dos Cruzados e do Santo Sepulcro" (Idem). Vê-se, com isso, que a referência militar em Edgard Armond é profunda.
} 
Religare, ISSN: 19826605, v.14, n.1, agosto de 2017, p. 28-59.

grupo que o comandante fez uma das suas mais importantes "descobertas": que os espíritos desencarnados no espaço seriam organizados em regimentos, segundo o tipo de tarefa a que são escalados. E cada batalhão, por assim dizer, recebe o nome de Fraternidade ${ }^{19}$.

Armond - orientado pelo espírito Razin, que teria pedido a ele que formasse um organismo em que as pessoas pudessem não só conhecer a história de Jesus, mas viver a sua mensagem - criou então, em 1950, a Escola de Aprendizes do Evangelho, na prática, um curso de dois anos voltado para estudos evangélicos e também doutrinários espíritas. Mas Razin (ou Armond, dá no mesmo), ainda não satisfeito, porque sabia que após a formatura dos alunos, eles seriam "tragados" pela sociedade, incentivou Armond a criar um outro organismo que os retivesse, ao menos os melhores alunos, para que eles pudessem colocar em prática todos os ensinamentos transmitidos no curso. Foi quando patrocinou, em 1952, a fundação da Fraternidade dos Discípulos de Jesus (FDJ), à imagem e semelhança da Fraternidade do Trevo, liderada pelo espírito Razin. Só que essa fraternidade surgia com uma novidade: a FDJ seria composta também por “espíritos encarnados", isto é, pelos ex-alunos da Escola de Aprendizes do Evangelho - já que em princípio, como revelara o comandante, uma fraternidade se constituía apenas de "espíritos desencarnados". A Escola de Aprendizes do Evangelho mais parecia seguir critérios próximos aos das doutrinas esotéricas, que cultivam certo interiorismo e tem no processo iniciático uma de suas fortes marcas.

No rol de suas importantes inovações, sem dúvida a criação de cursos espíritas merece destaque, e a própria história do espiritismo, ao menos paulista, pode ser dividida em pelo menos duas etapas: antes das tais escolas e depois delas. Claro que, ao longo do século XX, os cursos propostos por Armond se ampliaram ou se modificaram, a depender da instituição que os forneciam e ainda fornece, mas

\footnotetext{
${ }_{19}$ Para mais informações, ver: Arribas (2014, p. 173-175).
} 
Religare, ISSN: 19826605, v.14, n.1, agosto de 2017, p. 28-59.

o fundamental é reter que essa iniciativa começou com Armond e foi uma das grandes responsáveis em promover, de uma só tacada, (1) um envolvimento mais assíduo e consciente dos alunos com as instituições espíritas, (2) adesão maior ao espiritismo (3) certa uniformização das práticas, algo novo no movimento espírita de então.

Comandante Armond, feito um mistagogo, parece ser portador, por assim dizer, de um racionalismo místico e, por outro lado, do ideal da ordem e tranquilidade disciplinadas como padrão de valor absoluto. Nessa linha, quando o tipo de religiosidade em questão tende a se tornar de massa, popularizada, modificada em sentido mágico-soteriológico e adaptada às necessidades dos leigos, a tendência é o nascimento de uma doutrina esotérica, ou pelo menos com forte disposição para tal. Curioso notar que para além do fato de Armond ter desenvolvido toda uma estrutura pedagógica, ele elucubrou também um sistema de hierarquização dos adeptos, parelho ao da maçonaria. Os graus ou patentes que os espíritas recebem dependem do nível de envolvimento com a e de entendimento da doutrina. Para se ter uma ideia, na maçonaria existem, entre outros níveis, o Aprendiz, o Companheiro e o Mestre. No espiritismo de Edgard Armond, há o Aprendiz, o Servidor e o Discípulo.

Atrelada à Escola de Aprendizes do Evangelho, Armond criou também, através de "inspiração mediúnica", um sistema de avaliação moral chamado caderneta pessoal, na qual o "iniciado" - termo utilizado em detrimento de aluno deveria registrar suas descobertas no "complexo terreno interior". Caberia a ele, pois, identificar, listar e analisar em pormenores os resultados de suas reflexões para "armar-se contra as ameaçadoras feras que habitam o mundo íntimo" (Armond, 1988, p. 56). E o que era registrado na tal caderneta passaria ao final de cada ano letivo por um exame aplicado pelos dirigentes de cada turma com vistas à progressão do adepto. 
Religare, ISSN: 19826605, v.14, n.1, agosto de 2017, p. 28-59.

Preocupado, portanto, com a formação dos espíritas e dos médiuns, Armond deu origem, em 1949, ao Curso de Médiuns, iniciativa que rondava há tempos o meio espírita, mas sem grande sucesso ${ }^{20}$. Armond decidiu estruturar o curso, organizando a publicação do primeiro livro sistematizado, Pontos da Escola de Médiuns. O objetivo era dar ao médium as ferramentas para que ele pudesse "adestrar" as suas faculdades mediúnicas e se envolver de modo consciente com a doutrina.

Efetivamente, Edgard Armond não parou por aí. Quem olha para a sua trajetória pode facilmente enumerar uma série de iniciativas, muitas inovadoras, dentre as quais: (1) o Grupo de Vibrações; (2) as Preces Cantadas; (3) a fundação de O Semeador, periódico oficial da FEESP; (4) a criação, quando da saída de Armond da FEESP, da Aliança Espírita Evangélica (AEE), cujo órgão principal, o jornal (5) O Trevo, também fora criado por ele; (6) a importação da Inglaterra do CVV - Centro de Valorização da Vida; a introdução no campo da assistência espiritual da FEESP (7) da cromoterapia e de (8) práticas que hoje se convencionaram chamar de apometria (Silva Jr., 2010, p. 315); (9) a padronização dos passes; e, por fim, (10) inúmeros artigos e mais de 30 livros $^{21}$.

A seu modo, Armond se transformou em um dos artífices de um espiritismo de colorido esotérico, não só por meio dos cursos e organismos criados por ele e de suas publicações, mas também através da padronização de algumas práticas. Com a publicação, em 1950, de Passes e radiações e com a criação do Departamento de

\footnotetext{
${ }^{20}$ A ideia de instituir uma escola para o esclarecimento e o desenvolvimento dos médiuns aparece pela primeira vez no movimento espírita no final do século XIX com Bezerra de Menezes, de quem trataremos, neste artigo, mais adiante (Arribas, 2010, p. 258).

${ }^{21}$ Armond projetou definitivamente seu nome no cenário espírita com a publicação, em 1951, de seu best-seller Os exilados de Capela. O livro retrata a pré-história do nosso planeta, que estaria em plena integração cósmica, ao narrar a vinda de seus primeiros habitantes, os "capelinos", espíritos intelectualmente desenvolvidos vindos de Capela, estrela da constelação do Cocheiro. Vale dizer que em 1939, Chico Xavier havia psicografado o livro A caminho da luz, ditado por seu mentor espiritual Emmanuel, tocando no mesmo tema, embora em perspectiva mais ampla.
} 
Religare, ISSN: 19826605, v.14, n.1, agosto de 2017, p. 28-59.

Assistência Espiritual (DEPASSE) na FEESP dois anos depois, Armond apresentava técnicas de aplicação de passes elaboradas especialmente para cada tipo de necessidade do "paciente". É importante frisar que a sistematização dos passes, embora tenha recebido versões aqui e ali, tem em Armond um dos seus grandes precursores. E foi justamente nesse processo de organização da assistência espiritual que ele deu vazão a seus conhecimentos, promovendo a introdução e a vulgarização de termos e conceitos, tais como karma, chacras, plexo solar e duplo etéreo, elementos que hoje são considerados por muitos espíritas como parte integrante da doutrina, demonstrando, em certo sentido, o sucesso de suas inovações. Curioso notar que por mais que vasculhemos as obras de Kardec, não encontraríamos nada semelhante, pelo menos não nesses precisos termos.

Não estamos entrando no mérito da aceitação ou não de suas iniciativas, mas é possível atinar para o fato de que nem todas as "ordens" do comandante seriam pronta e pacificamente aceitas. Porém, apesar disso, muito do que ele trouxe para o espiritismo ficou e a legitimidade que angariou ao longo de seu comando foi importante para manter e expandir um tipo de espiritismo bastante particular. Não causa estranheza Armond ter abraçado e difundido as ideias trazidas por outro espírito de origem oriental chamado Ramatís ${ }^{22}$, nos anos 1950. Embora os escritos de Ramatís dividam opiniões e adeptos espíritas até hoje, Armond não vacilou hora alguma em defendê-lo, tamanha afinidade que encontrou em suas ideias.

Sem tréguas, as inúmeras táticas postas em ação por Armond nos ajudam a perceber com mais clareza quão dinâmico e plural é o espiritismo brasileiro. As formas de orientação religiosa, as direções da ação no mundo, os mecanismos de legitimação, as maneiras de atingir a salvação, tudo isso varia sensivelmente dentro

\footnotetext{
${ }_{22}$ Manifestava-se através da mediunidade do paranaense Hercílio Maes.A querela que permeava o meio espírita vem justamente do fato de Ramatís trazer mais outras tantas inovações de ordem esotérica, valorizar a influência dos astros sobre os comportamentos humanas e concorrer com novas contribuições orientalistas, dissonantes das obras kardecianas.
} 
Religare, ISSN: 19826605, v.14, n.1, agosto de 2017, p. 28-59.

do espectro religioso a que se convencionou chamar de espiritismo. O entendimento de uma religiosidade mais mística, abraçada por Armond, não obstante tenha igualmente suas exigências éticas, tende a um caráter substancialmente mágicosacramental, tendo a progressão hierárquica entre os adeptos um papel importante. $\mathrm{O}$ respeito às insígnias e aos simbolismos fazem parte do processo de aperfeiçoamento do "aprendiz" que, à medida que se aprofunda na doutrina, se torna "servidor" e mais tarde "discípulo". A educação espírita nesses moldes visaria, pois, espiritualizar os homens e essa espiritualização dependeria, em grande parte, do esforço individual de renovação moral. Esse seria o objetivo do espiritismo, a sua "missão cósmica" (Armond, 1988, p.41).

A tendência a uma religiosidade de traços místicos, própria do comandante, inaugurou um espaço para práticas até então inusitadas no espiritismo e com elas vieram as ramificações. O ramatisismo (seguidores de Ramatís) pode ser encarado como exemplo. Não estamos dizendo com isso que esse ou outros grupos espíritas sigam conscientemente as pegadas de Armond ou que sejam seus herdeiros assumidos. A ideia é antes apontar para a abertura que a visão de espiritismo do comandante, que apareceu de forma inaugural no cenário, possibilitou aos que vieram depois dele ${ }^{23}$. Mais tarde, com a diversificação do movimento espírita, acabou por crescer numa franja dele um grande número de simpatizantes de práticas como o uso de cristais, tarô, Reiki, florais de Bach, fitoterapia, numerologia, acupuntura etc. Desde então, elas só vêm se multiplicando, não sem antes contar com adversários e partidários, contribuindo, desse modo, para tornar plural o espiritismo brasileiro.

\footnotetext{
${ }^{23}$ Não ignoramos que na literatura acadêmica existam estudos sobre a relação entre espiritismo e espiritualismo (Stoll, 2003) ou espiritismo e Nova Era (D'Andrea, 2000). Ocorre que em nenhum desses estudos a figura de Edgard Armond é mencionada como uma espécie de precursor, seja de uma visão com tendências ao espiritualismo/esoterismo/orientalismo, seja de uma visão propícia à aproximação de elementos estilo New Age.
} 
Religare, ISSN: 19826605, v.14, n.1, agosto de 2017, p. 28-59.

\section{4. $O$ crescente cultivo do Novo Testamento}

O traço religioso-cristão do espiritismo está registrado principalmente no livro O evangelho segundo o espiritismo, publicado por Allan Kardec em 1864. Tal obra reúne trechos dos quatro evangelhos canônicos, além de comentários do próprio codificador e mensagens espirituais sistematizadas por ele, após terem sido psicografadas por diferentes médiuns. Considera-se, nesse meio, que a afirmação da identidade religiosa do espiritismo ocorreu apenas após a filosófica, com O livro dos espiritos (1857), e a científica, com O livro dos médiuns (1961).

Um dos primeiros adeptos do espiritismo - contemporâneo de Kardec e igualmente francês - o advogado Jean-Baptiste Roustaing, publicou em quatro volumes, no ano de 1866, um livro intitulado Os quatro evangelhos: revelação da revelação, contendo observações dele próprio e mensagens psicografadas por uma única médium belga chamada Émilie Collignon. Na controvertida obra, Roustaing afirma que Jesus Cristo não teria efetivamente nascido e tampouco possuído um corpo físico, mas sim um "corpo fluídico" (Souto Maior, 2013, p. 293-294). Seu livro teve grande influência sobre lideranças espíritas brasileiras do século XIX. Sobremaneira no Rio de Janeiro houve disputa entre um segmento voltado para o estudo de sua obra junto com as de Kardec e outro voltado para a reflexão exclusiva sobre os textos publicados pelo fundador espírita, com viés cientificista e ênfase nas experimentações mediúnicas (Arribas, 2010). No primeiro grupo, sobressaiu o médico cearense, radicado no Rio de Janeiro, Adolfo Bezerra de Menezes Cavalcanti, um dos principais articuladores da formação da FEB em 1884, tornando-se seu presidente cinco anos mais tarde e também depois, de 1895 até falecer em 1900 (Carvalho e Carvalho, 2017). Conhecido como "médico dos pobres" pelo atendimento gratuito a pessoas carentes e fervoroso defensor do trabalho assistencial espírita, Menezes foi o principal artífice da contraposição religiosa à linha cientificista, bem como da unificação espírita em torno da FEB (Arribas, 2010). 
Religare, ISSN: 19826605, v.14, n.1, agosto de 2017, p. 28-59.

Ao longo do século $\mathrm{XX}$, o movimento espírita brasileiro foi deixando de lado a referência a Roustaing em prol da exclusividade de Kardec.

Outro protagonista na afirmação do espiritismo como religião cristã foi Chico Xavier $^{24}$. Responsável por mais de quatro centenas de livros psicografados cujos direitos autorais foram doados (Lewgoy, 2004), ele publicou em 1938 a obra Emmanuel, primeira ditada exclusivamente por seu mentor espiritual, com o mesmo nome do livro. No texto, o guia de Xavier discorre sobre diversos assuntos, entre eles: as contradições católicas, a ascendência da mensagem de Jesus Cristo, a base religiosa do espiritismo e a formação da mentalidade cristã. Dois anos depois, a dupla publicou o primeiro de uma série de quarto romances históricos sobre o cristianismo, intitulado Há dois mil anos. Compõe esta série o romance tido pelo próprio Chico Xavier como sua principal obra mediúnica: Paulo e Estêvão (1942), que narra a trajetória de Paulo de Tarso e é considerado, no meio espírita, um complemento ao livro bíblico Atos dos apóstolos e também às epístolas paulinas.

Em 1948, com a publicação de Caminho, verdade e vida, Emmanuel e Chico Xavier iniciaram outra série, desta vez de oito obras ao todo ${ }^{25}$, sendo elas compostas por comentários de versículos retirados do Novo Testamento, abrangendo: evangelhos, Atos dos apóstolos, cartas apostólicas e Apocalipse. Tais obras se tornaram bastante estudadas em diversos centros espíritas espalhados pelo país. Mas foi a publicação de Jesus no lar (1950), ditado a Xavier pelo espírito Neio Lúcio, que ensejou o desenvolvimento de uma prática bastante constitutiva do movimento espírita brasileiro: o Culto do Evangelho no Lar. Baseando-se nesse livro - que relata o estudo da Bíblia hebraica por Cristo junto com a família do apóstolo Pedro, na casa

\footnotetext{
${ }^{24}$ Considerado por muitos espíritas como o maior médium da história, ele contou com o apoio relevante de algumas pessoas, entre elas o também mineiro Arnaldo Rocha, que coordenava as reuniões mediúnicas das quais Xavier participava.

${ }_{25}$ As demais são: Pão nosso (1950), Vinha de luz (1951); Fonte viva (1956); Palavras de vida eterna (1964); Bênção de paz (1971); Segue-me!... (1973); Ceifa de luz (1979).
} 
Religare, ISSN: 19826605, v.14, n.1, agosto de 2017, p. 28-59.

deste - Chico Xavier começou ele próprio a fazer o mesmo em sua cidade natal, Pedro Leopoldo, junto à família de seu chefe na Fazenda Modelo, ligada ao Ministério da Agricultura, Rômulo Joviano ${ }^{26}$. Fazendo o estudo de $O$ evangelho segundo o espiritismo ${ }^{27}$ rodeado por pessoas, às vezes ao ar livre, o médium mineiro propagou tal prática, que veio se tornar comum em famílias adeptas dessa religião no Brasil, estando também na origem de diversos centros espíritas.

Em Belo Horizonte, distante apenas $42 \mathrm{~km}$ da cidade de Chico Xavier, foi constituído um relevante centro espírita com o nome de Grupo Emmanuel, no ano de 1957, exatamente um século após o surgimento do espiritismo na França ${ }^{28}$. Formado por militantes espíritas que obtiveram certo renome nesse meio religioso - Honório Onofre Abreu, sua esposa Nilza Ferreira de Abreu, Leão Zállio e José Damasceno Sobral - aquela instituição desenvolveria outra prática nova no âmbito do movimento espírita brasileiro: o estudo pormenorizado dos textos que compõem o Novo Testamento ${ }^{29}$. Em decorrência desse trabalho, Honório Abreu organizou o livro Luz imperecível: estudo interpretativo do evangelho à luz da doutrina espírita. Nesta obra, é esmiuçada a maneira como se dava tal estudo:

\footnotetext{
${ }^{26}$ Revelações da psicografia de Xavier apontam que Neio Lucio - personagem do segundo romance histórico de Emmanuel, Cinquenta anos depois (1940), referente ao século II - foi uma reencarnação do pai de Rômulo, chamado Artur Joviano (Joviano, 2008; Joviano e Lemos Neto, 2014). Vale dizer que o quarto romance daquela série foi Renúncia (1943), com uma narrativa da qual o espírito Lucio também faz parte.

27 Cabe dizer que nesta obra Kardec busca demonstrar que conceitos espíritas, tais como reencarnação e pluralidade dos mundos habitados, estão inscritos na Bíblia. Isso contribui bastante para que a maioria dos espíritas não leia diretamente aqueles que são considerados os principais textos bíblicos, acreditando-se que o estudo do livro kardeciano, por si só, é suficiente.

${ }^{28}$ Vale dizer que também naquele ano, Emmanuel e Chico Xavier publicaram o livro Religião dos espíritos, em homenagem ao centenário da primeira obra de Kardec. O mentor de Xavier e outros espíritos considerados superiores afirmaram ser o espiritismo uma espécie de caminho para a "religião do amor e da sabedoria".

${ }^{29}$ Conta-se no meio espírita que o método de análise dos textos bíblicos, chamado de "Colar de pérolas" e iniciado nesse grupo, reconstitui o que fizera o espírito Emmanuel durante sua reencarnação no século XVII como o espanhol padre Damiano, conforme o livro Renúncia.
} 
Religare, ISSN: 19826605, v.14, n.1, agosto de 2017, p. 28-59.

O primeiro passo será sempre entender bem o aspecto literal do texto. Para isso, promover atenciosa leitura, considerando o significado exato de cada palavra, tempo e pessoas dos verbos, lugar, ocasião, circunstâncias, profissões e cargos, expressões e hábitos vigentes à época de Jesus, utilizando-se, se necessário, de dicionários (Abreu, 2001, p.21).

Abreu foi presidente da federativa estadual, a União Espírita Mineira (UEM), de 2003 até falecer em 2007. E foi justamente durante aquele período que ele fez intermediação para o início de outra fase em termos de estudos bíblicos no espiritismo, inclusive em âmbito internacional. Seu principal discípulo, o juiz de direito Haroldo Dutra Dias, auxiliava-o e também Marta Antunes, dirigente da FEB, na elaboração de uma apostila integrante do conjunto chamado Estudo Aprofundado da Doutrina Espírita (EADE), produzido pela federativa nacional ${ }^{30}$, então conduzida por Nestor Masotti. Sem saber qual das traduções da Bíblia escolher para a elaboração de tal material, Masotti consultou Honório Abreu e Haroldo Dias a respeito. Tendo estudado grego e hebraico na Universidade Federal de Minas Gerais, Dias foi levado por Abreu a assumir o compromisso de fazer uma tradução própria, que seria ao menos dos evangelhos, direto do grego. Para tanto, ele empreendeu uma viagem a Israel, patrocinada pela FEB, para comprar meia tonelada de livros e iniciar a formação de uma biblioteca bíblica. Esse trabalho de pesquisa propiciou que a tradução ficasse pronta e fosse publicada pelo CEI (e depois pela FEB) em 2010, mesmo ano em que se comemorou intensamente, nessas organizações, o centenário de nascimento de Chico Xavier. Haroldo Dias passou então a ter uma intensa agenda de palestras, também no exterior, ressaltando que aquela se tratava de uma tradução literal - com notas de rodapé, sem viés teológico ou doutrinário - e afirmando também seu compromisso de ainda traduzir, também do grego, as demais partes do Novo Testamento.

\footnotetext{
30 Versando sobre as parábolas dos evangelhos, o trabalho em relação àquela apostila propiciaria a Dias publicar mais tarde, em 2014, um livro intitulado: Parábolas de Jesus: texto e contexto.
} 
Religare, ISSN: 19826605, v.14, n.1, agosto de 2017, p. 28-59.

No ano seguinte, Haroldo Dias fundou com alguns amigos - sobretudo Júlio Adriano Corradi e Thiago Franklin, também de Belo Horizonte - a Sócio Organização de Espiritualidade e Religiosidade, o Instituto SER (Aguiar, 2016). Tal instituição realiza seminários, palestras, disponibilizando textos, áudios e vídeos na internet, além de comercializar parte desses conteúdos, assim como livros, CDs e DVDs. Em 2012, o Instituto Ser realizou um seminário lítero-musical em comemoração aos setenta anos do livro Paulo e Estêvão, tema que predomina nas entrevistas e palestras de Dias ${ }^{31}$. Ao lado de Divaldo Franco, Haroldo Dias aparece em congressos e demais eventos espíritas, também internacionais, como o principal conferencista.

Dias também vem se destacando no meio espírita através de eventos voltados para o diálogo inter-religioso, com base numa identidade comum cristã. Ele é amigo próximo do, também belo-horizontino, além de livreiro e pastor batista, Enéas Alexandrino e da freira católica Aíla Pinheiro de Andrade, madre superiora do Instituto Religioso Nova Jerusalém, doutora em teologia e professora piauiense fixada em Fortaleza. Desde 2011, os três vêm participando de programas televisivos de emissoras laicas e também de seminários organizados por federativas estaduais e demais organizações espíritas, difundindo o estudo bíblico neste meio religioso (Souza, 2015; Aguiar, 2016).

Outro discípulo de Honório Abreu, quanto ao estudo sistematizado do Novo Testamento combinado à doutrina espírita, é o funcionário público do governo estadual mineiro, Wagner Gomes da Paixão. Natural de Belo Horizonte tal como Dias, Paixão é médium reconhecido no movimento espírita como transmissor de mensagens também em psicofonia de Chico Xavier $^{32}$. É responsável por vinte quatro

\footnotetext{
${ }^{31}$ Em tal obra, sobre a trajetória do apóstolo Paulo, é narrada a formação de comunidades cristãs (igrejas) em diversas localidades a partir de reuniões domésticas de estudo evangélico.

32 Durante o III Congresso Espírita Brasileiro, realizado em Brasília no ano de 2010, Wagner Paixão psicografou uma mensagem de Xavier e outra de Juscelino Kubitschek.
} 
Religare, ISSN: 19826605, v.14, n.1, agosto de 2017, p. 28-59.

livros de autoria atribuída a diversos espíritos, dentre eles: Honório Abreu, Leão Zállio, Bezerra de Menezes e Emmanuel, sendo que a primeira obra deste autor espiritual, Iluminação (1999), recebeu aval de Chico Xavier antes de ele vir a falecer em 2002. Paixão também faz muitas palestras em viagens internacionais e seus vídeos na internet, inclusive coordenando estudos do Novo Testamento, são bastante acessados.

Em 2012, Haroldo Dias e Wagner Paixão foram convidados pelo então presidente da FEB, Antonio Cesar Perri de Carvalho - que havia substituído o também paulista João Masotti antes de seu falecimento um ano antes - para constituírem em Brasília um grupo de estudos sistematizados do Novo Testamento, ligado à federativa nacional. Recebendo o nome de Núcleo de Estudos e Pesquisas do Evangelho (NEPE), tal grupo teve como fundadores os próprios Dias, Paixão, Perri e sua esposa e filho, respectivamente: Célia Maria Rey de Carvalho e Flávio Rey de Carvalho, além dos demais militantes e estudiosos bíblicos espíritas, o catarinense Ricardo de Andrade Mesquita e os mineiros: Simão Pedro de Lima ${ }^{33}$ e Afonso Chagas Correa. Caberia também ao NEPE, ligado à FEB, opinar sobre o uso de todo material bibliográfico trazido por Haroldo Dias de Israel. Até Cesar Perri deixar a presidência da FEB em 2014, tal grupo realizou reuniões de estudo cujos vídeos foram publicados no youtube. No entanto, outros NEPEs surgiram em diferentes localidades. Até março de 2017, foram levantadas catorze unidades desse tipo, espalhadas cada qual numa cidade diferente de sete estados: Alagoas, Amazonas, Minas Gerais, Paraíba, Rio de Janeiro, Rio Grande do Sul e São Paulo ${ }^{34}$.

\footnotetext{
${ }_{33}$ Natural da cidade mineira de Patrocínio, também se destaca pelo estudo aprofundado do Novo Testamento e pelos vários vídeos de palestras disponíveis no youtube.

34 Há também no âmbito do movimento espírita nacional alguns grupos de estudo do Novo Testamento que se autodenominam de "Estudo Minucioso do Evangelho de Jesus (EMEJ)" e "Miudinho" sendo este o mesmo termo com o qual Honório Abreu e membros do Grupo Emmanuel apelidaram suas reuniões de estudo bíblico. Há diversos vídeos de estudo com tal nome, disponíveis no youtube e também no site do Instituto Ser (www.portalser.org), conduzidos por Aluízio Ferreira Elias, também mineiro, de Uberaba, cidade onde se fixou Chico Xavier. Elias é reconhecido por
} 
Religare, ISSN: 19826605, v.14, n.1, agosto de 2017, p. 28-59.

Em comemoração aos 150 anos de publicação da obra kardeciana $O$ evangelho segundo o espiritismo, a FEB realizou cursos a seu respeito e lançou uma coleção de sete volumes reunindo os textos do espírito Emmanuel publicados em diferentes livros, sendo todos a respeito do Novo Testamento. Organizada por Saulo Cesar Ribeiro da Silva - membro do NEPE/FEB - e denominada O evangelho por Emmanuel, essa coleção conta com comentários a respeito dos evangelhos de: (1) Mateus; (2) Marcos; (3) Lucas; (4) João; e também das cartas (5) de Paulo e (6) cartas universais; além do (7) Apocalipse. Lançada em Campo Grande (MS) no mês de abril daquele ano, durante o $4^{\circ}$ Congresso Espírita Brasileiro, ela veio a esgotar a edição de três mil exemplares em apenas três semanas. Tendo como significado de seu nome a expressão "Deus conosco", Emmanuel é evidentemente considerado, no meio espírita, o maior intérprete do Novo Testamento ${ }^{35}$.

Como se pode ver, há uma trajetória de difusão do estudo do Novo Testamento no movimento espírita que foi iniciada em meados do século XX e ganhou novo impulso na primeira década do presente centenário. Desde Chico Xavier, passando por Honório Abreu até os atores atuais, sobremaneira Haroldo Dias - bastante reconhecido por apontar a necessidade de os espíritas se apropriarem do texto bíblico - há um protagonismo mineiro em tal empreitada, ressaltando a identidade religiosa e cristã do espiritismo ${ }^{36}$. Algumas vezes, tido ainda como "igrejeiro" e "carola", sobretudo pelas reencarnações como padre ${ }^{37}$, Emmanuel cumpre um papel fundamental em tal entonação espírita no Brasil.

muitos militantes espíritas como o maior conhecedor da metodologia de estudo empregada por Abreu.

35 Também sobre o Novo Testamento, cabe fazer menção também a um livro psicografado por Chico Xavier, mas de diferente autor espiritual, Boa nova (Humberto de Campos), e a duas obras não mediúnicas: Parábolas e ensinos de Jesus (Cairbar Schutel) e Primícias do reino (Amélia Rodrigues).

${ }^{36}$ Como visto, embora exista desde 1950 uma iniciativa relevante na capital paulista com a Escola de Aprendizes do Evangelho, tal empreitada se mostrou sem o mesmo grau de profundidade no estudo dos evangelhos e tampouco sem a gramde referência no espírito Emmanuel.

${ }^{37}$ Uma delas sendo Manoel da Nóbrega, um dos fundadores da cidade de São Paulo (Tavares, 1986; Joviano e Lemos Neto, 2014). 
Religare, ISSN: 19826605, v.14, n.1, agosto de 2017, p. 28-59.

Através dos livros oriundos de sua parceria com Xavier, do pioneiro grupo de estudo bíblico que recebeu seu nome e dos atuais militantes dedicados ao cultivo do Novo Testamento, o espiritismo vem se colocando cada vez mais, ao lado do catolicismo e do protestantismo, como uma religião voltada para o "Evangelho".

\section{Considerações finais}

Há um século e meio o espiritismo chegava ao Brasil. Se naquele momento as obras de Allan Kardec eram quase as únicas referências com as quais contavam os primeiros espíritas, de lá para cá, muita coisa mudou. O espiritismo dispõe hoje de uma ampla malha de instituições, centros, federações e publicações, tendo se tornado diversificado em termos de personagens, temas e também dilemas.

Embora o espiritismo se apresente, ao menos para o senso comum e idealizador, como um conjunto uno e harmonioso, sua dinâmica interna nos revela o permanente processo de reinvenção e rearticulação, resultado de frequentes e intensos diálogos, a depender do momento histórico e dos personagens envolvidos, conquanto seus diferentes adeptos clamem constantemente por sua unificação teórica, prática e institucional. Em todos os momentos, porém, a tríplice dimensão espírita pautou as discussões e ensejou disputas internas, levando os diferentes atores a um jogo duplo: de enunciação doutrinal, assim como de definição e de consolidação do lugar de enunciação legítima.

Particularmente férteis são as discussões no Rio de Janeiro, em São Paulo e em Minas Gerais. Ainda que a divisão entre as ênfases: filosófica, científica e religiosa não seja de todo excludente, tratando-se, antes, de diferenças de abordagem, o estudo aprofundado dessa dinâmica nos revela que mesmo em cada tipo de apropriação existem formas plurais, e não raras vezes divergentes. Entre os mais afeitos à dimensão religiosa, por exemplo, a pluralidade de interpretações pode oscilar entre um espiritismo místico-esotérico, que teve em Edgard Armond e em seu guia espiritual Razin os representantes mais prolíficos, e um espiritismo 
Religare, ISSN: 19826605, v.14, n.1, agosto de 2017, p. 28-59.

densamente evangélico, representado principalmente por Chico Xavier e seu mentor Emmanuel. Essa pluralidade também ocorre entre os que pendem para o lado científico. Oriundos do mundo acadêmico ou angariando legitimidade através de suas ocupações profissionais, os militantes que enfatizam a compreensão científica do espiritismo contam igualmente com apropriações e fontes de legitimação distintas, tanto mais quando olhamos para aqueles em que a "revelação científica" - como é o caso de Divaldo Franco e sua guia espiritual Joanna de Ângelis - mesclam discussões de fundo científico com revelação trazidas pelos espíritos. Por vezes se fala ainda no meio espírita, não tão abertamente, sobre um embate entre o que é considerado cientificismo, esoterismo e igrejismo. Embora seja crescente a ênfase no estudo bíblico e no cultivo do Evangelho, observa-se a diversidade de atores, grupos e apropriações, algo que evidencia quão variado é hoje o espiritismo brasileiro.

\section{Referências}

ABREU, Honório Onofre. Luz imperecível: estudo interpretativo do evangelho à luz da doutrina espírita. 4⿳亠丷a edição. Belo Horizonte: UEM, 2001.

AGUIAR, José Otávio. Do miudinho ao SER: uma história do movimento espírita brasileiro em suas recentes expressões midiáticas (2011-2016). In: RODRIGUES, André Figueiredo; AGUIAR, José Otávio. História, religiões e religiosidade: da antiguidade aos recortes contemporâneos e debates sobre religiões. São Paulo, Humanitas, 2016.

ARAUJO, Augusto César Dias de. Espiritismo, esta loucura do século XIX: ciência, filosofia e religião nos escritos de Allan Kardec. São Paulo/Juiz de Fora: Fonte Editorial/PPCIR, 2016.

ARRIBAS, Célia da Graça. Afinal, espiritismo é religião? São Paulo: Alameda, 2010.

. O caráter religioso do espiritismo. Fragmentos de Cultura. v. 23, nº1, jan-mar, 2013. p. 3-16

. No princípio era o verbo: espíritas e espiritismos na modernidade religiosa brasileira.

Tese (Doutorado em Sociologia), USP, São Paulo, 2014.

ARMOND, Edgard. Vivência do espiritismo religioso. São Paulo: Aliança, 1988 (2006). 
Religare, ISSN: 19826605, v.14, n.1, agosto de 2017, p. 28-59.

. Prática mediúnica. São Paulo: Aliança, 2002.

. Passes e radiações. São Paulo: Aliança, 1999.

ARMOND, Ismael. Edgard Armond, meu pai. A história do homem que criou as escolas de espiritismo no Brasil. São Paulo: Aliança, 2001.

. Edgard Armond, um trabalhador na seara espírita. São Paulo: Aliança, 2002.

CAMURÇA, Marcelo et. al. O “Espiritismo Racional e Científico Cristão" de Luiz Mattos dos anos 1910-1920 no Brasil. In: SOUZA, André Ricardo de; SIMÕES, Pedro; TONIOL, Rodrigo (Orgs.). Espiritualidade e espiritismo: reflexões para além da religiosidade. São Paulo: Porto de Ideias, 2017.

CARVALHO, Flávio Rey de; CARVALHO, Antonio Cesar Perri de. Espiritismo como religião: algumas considerações sobre seu caráter religioso e seu desenvolvimento no Brasil. In: SOUZA, André Ricardo de; SIMÕES, Pedro; TONIOL, Rodrigo (Orgs.). Espiritualidade e espiritismo: reflexões para além da religiosidade. São Paulo: Porto de Ideias, 2017.

CERQUEIRA FILHO, Alírio. Fora da caridade não há salvação. São Paulo: Editora Bezerra de Menezes, 2009.

. Terra: um mundo em Regeneração. Mato Grosso: Espiritizar, 2012.

D’ANDREA, Anthony. O Self Perfeito e a Nova Era. São Paulo: Loyola, 2000.

GIUMBELLI, Emerson. O cuidado dos mortos: uma História da Condenação e Legitimação do Espiritismo. Rio de Janeiro; Arquivo Nacional, 1997.

JOVIANO, Wanda Amorim (Org.). Sementeira de luz. Belo Horizonte: Vinha de Luz, 2008.

JOVIANO, Wanda Amorim (Org.). Deus conosco. Belo Horizonte: Vinha de luz, 2014.

KLINJEY, Rossandro. As 5 faces do perdão. s.l, Letra Mais, 2016.

LEWGOY, Bernardo. O grande mediador: Chico Xavier e a cultura brasileira. Bauru: EDUSC; Brasília: CNPq-PRONEX, 2004.

- A contagem do rebanho e a magia dos números: nota sobre o espiritismo no Censo 2010. In: TEIXEIRA, Faustino \& MENEZES, Renata (Orgs.). Religiões em movimento: o censo de 2010. Petrópolis, Vozes, 2013, p. 191-202.

- Uma religião em trânsito: o papel das lideranças kardecistas na transnacionalização do espiritismo brasileiro. Ciencias Sociales y Religión (Impresso), v. 13, 2011, p. 93-117,

. Representações de ciência e religião no espiritismo kardecista. Civitas, 6 (2), jul-dez, 2006. p. 151-167. 
Religare, ISSN: 19826605, v.14, n.1, agosto de 2017, p. 28-59.

- A transnacionalização do espiritismo kardecista brasileiro. Religião $e$ Sociedade. 28 (1), 2008. p. 84-104

MOREIRA, Andrei. Autoamor e outras potências da alma. Belo Horizonte: AME, 2012.

SAMPAIO, Jader. Ethos, Sincretismo e identidade do espiritismo Brasileiro. Jornal de Estudos Espíritas. v. nำ. 2014. p. 1-8.

SIGNATES, Luiz. Cisma religioso e disputa simbólica: tensão comunicacional no espiritismo brasileiro e panamericano. Fragmentos de Cultura. 23 (1), jan-mar, 2013. pp. 39-50

. Espiritismo e Racionalidade. Fragmentos de Cultura. 24 (4), out-dez, 2014. p. 435-450.

SILVA JR., Edelso. No tempo do comandante. Edgard Armond e o espiritismo em época de revolução. São Paulo: Editorial Espírita Radhu, 2010.

SIMÕES, Pedro. Dá-me de comer. São Paulo: LIHPE/CCDPE-ECM, 2015.

SOUTO MAIOR, Marcel. Kardec: a biografia. Rio de Janeiro: Record, 2013.

SOUZA, André Ricardo de. O diálogo cristão entre católicos, evangélicos e espíritas. Trabalho apresentado no $28^{\circ}$ Congresso Internacional da SOTER. Belo Horizonte, 2015.

STOLL, Sandra Jaquecline. Espiritismo à brasileira. São Paulo: Edusp, 2003.

TAVARES, Clóvis. Amor e sabedoria de Emmanuel. 6ae ed. Araras: IDE, 1986.

XAVIER, Francisco Cândido. Nos domínios da mediunidade. Rio de Janeiro: FEB, 1955. (Ditado pelo espírito Emmanuel) . Evolução em dois mundos. Rio de Janeiro: FEB, 1958 (Ditado pelo espírito Emmanuel). 